\title{
Curcumin inhibits the viability, migration and invasion of papillary thyroid cancer cells by regulating the miR-301a-3p/STAT3 axis
}

\author{
YING LIANG $^{1 *}$, DEYU KONG $^{2 *}$, YI ZHANG $^{1}$, SIQI LI $^{1}$, YAN LI $^{1}$, \\ LIYING DONG ${ }^{1}$, NINGXIN ZHANG ${ }^{1}$ and JUNFENG MA ${ }^{1}$ \\ ${ }^{1}$ Department of Thyroid and Breast Surgery, The Second Affiliated Hospital of Kunming Medical \\ University, Kunming, Yunnan 650101; ${ }^{2}$ Department of Internal Medicine-Oncology, The First \\ Affiliated Hospital of Kunming Medical University, Kunming, Yunnan 650032, P.R. China
}

Received October 30, 2020; Accepted May 19, 2021

DOI: 10.3892/etm.2021.10307

\begin{abstract}
Thyroid cancer is one of the most common malignant tumors, and the mortality rate associated with thyroid cancer has been increasing annually. Curcumin has been reported to exert an antitumor effect on papillary thyroid cancer (PTC), and the identification of additional mechanisms underlying the anticancer effect of curcumin on PTC requires further investigation. The present study aimed to explore the effects of curcumin on the viability, migration and invasion of PTC cells. TPC-1 cells were incubated with different concentrations of curcumin, and then, cell viability, migration and invasion, and wound healing were examined by CCK-8, Transwell and wound healing assays, respectively. Subsequently, microRNA (miR)-301a-3p mimics, miR-301a-3p inhibitors and signal transducer and activator of transcription (STAT)3 overexpression vector were transfected into TPC-1 cells, and cell viability, migration, and invasion were reassessed in these transfected cells. Matrix metallopeptidase (MMP)-2, MMP-9, epithelial-mesenchymal transition (EMT)-related markers, and Janus kinase (JAK)/STAT signaling pathway components were assessed by western blot analysis. Curcumin significantly inhibited cell viability, migration and invasion and downregulated MMP-2, MMP-9 and EMT marker expression. Additionally, curcumin decreased STAT3 expression by upregulating miR-301a-3p expression, and the inhibition of miR-301a-3p and the overexpression of STAT3 reversed the
\end{abstract}

Correspondence to: Ms. Junfeng Ma, Department of Thyroid and Breast Surgery, The Second Affiliated Hospital of Kunming Medical University, 1228 Beijing Road, Kunming, Yunnan 650101, P.R. China

E-mail: majunfeng00@sina.com

${ }^{*}$ Contributed equally

Key words: curcumin, thyroid cancer, microRNA-301a-3p, STAT3, JAK/STAT effects of curcumin on cell viability, migration and invasion, and MMP-2, MMP-9 and EMT marker expression in TPC-1 cells. Furthermore, curcumin suppressed the JAK/STAT signaling pathway through the miR-301a-3p/STAT3 axis. The data of the present study indicated that curcumin could inhibit the viability, migration and invasion of TPC-1 cells by regulating the miR-301a-3p/STAT3 axis. These findings may provide a possible strategy for the clinical treatment of PTC.

\section{Introduction}

Thyroid cancer is one of the most common malignant tumors, accounting for approximately $95 \%$ of all endocrine cancer cases and 3\% of all other cancer cases (1). The age-standardized mortality rate worldwide was $0.35 / 10^{5}$ in 2015 (2). According to the American Cancer Society, in the United States, $\sim 52,890$ new cases of thyroid cancer were estimated in 2020 , the number of female patients was projected to reach 40,170 cases, and the number of new cases in males was estimated to reach 12,720 (1). Thyroid cancer is histologically classified into 5 types. Papillary thyroid cancer (PTC) and follicular thyroid cancer (FTC) are the most common well-differentiated thyroid carcinomas, and these types of cancer generally have satisfactory prognosis and can be efficiently treated by conventional therapies (3). However, anaplastic thyroid cancer (ATC), poorly differentiated thyroid cancer (PDTC) and medullary thyroid cancer (MTC) may differentiate into more aggressive diseases that do not respond adequately to conventional therapies, ultimately leading to poor patient survival (4). Surgery and endocrine therapies play vital roles in the treatment of thyroid cancer. However, some patients have increased tumor invasiveness, which causes poor therapeutic efficacy and great pain (5). Therefore, an effective treatment or specific therapeutic strategy is urgently needed for the improved management of this malignancy.

Herbs (also known as botanicals), vitamins, minerals and probiotics have been used as complementary and alternative medicines in the treatment of cancer (6). Traditional Chinese medicine (TCM) has been reported to be an effective method 
for treating malignant tumors $(7,8)$. TCM has been revealed to reduce the production of drug resistance and provoke less damage and fewer side effects in patients. Curcuma longa (C. Longa) Linn is a Zingiberaceae plant, and its antitumor effects have been reported in thyroid (9), lung (10) and colorectal cancer cells (11). Curcumin is a main phenolic active compound in $C$. Longa Linn, and it has numerous pharmacological activities such as anti-inflammatory (12), antibacterial (13) and, especially, anticancer activities (14). The anticancer effects of curcumin are due to targeting a wide range of cellular and molecular pathways involved in cancer pathogenesis (15). For example, curcumin has been revealed to induce endoplasmic reticulum stress-associated apoptosis in human PTC cells via disruption of intracellular calcium homeostasis (16) and to affect PTC cells by targeting the JAK/STAT3 signaling pathway (17). Thus, the identification of additional mechanisms underlying the anticancer effect of curcumin on PTC requires further investigation.

MicroRNAs (miRNAs or miRs) are a group of noncoding RNAs that have been developed as novel biomarkers for the diagnosis and treatment of thyroid carcinoma (18). In previous studies, a variety of tumor-related miRNAs have been reported to participate in the development and diagnosis of cancer, including PTC $(19,20)$. Studies have demonstrated that miRNAs can act as either oncogenes or tumor suppressors in cancer. For instance, miR-301a-3p suppressed the progression of hepatocellular carcinoma by targeting VGLL4 (21). miR-486-5p was revealed to be highly expressed in PTC and promoted PTC cell invasion by influencing epithelial-mesenchymal transition (EMT) via targeting of KIAA1199 (22). However, miR-188-5p was demonstrated to be expressed at low levels in PTC, and restoration of its expression suppressed PTC cell proliferation (23). Interestingly, a previous study reported that curcumin exerted anticancer effects by regulating miRNAs (24), and caused a strong and significant reduction in miR-221, miR-222 and miR-21 (25). Functional miRNAs have been indicated to regulate target genes or proteins (26). The constitutive activation of Janus kinase/signal transducer and activator of transcription (JAK/STAT) has been revealed to play a vital role in the cell biological behavior and immune response associated with cancer progression $(27,28)$. The JAK/STAT signaling pathway has been demonstrated to be involved in the oncogenesis related to thyroid cancer and is considered to be a potential prognostic biomarker and therapeutic target $(17,29)$. In addition, emerging evidence has indicated that STAT3 is related to proliferation, migration and invasion in PTC (30-32). Interestingly, a recent study reported that curcumin inhibited the viability and migration of PTC cells by targeting the JAK/STAT3 signaling pathway (17), which may be a potential therapeutic target for PTC.

In the present study, the antitumor effects of curcumin on a PTC cell line (TPC-1) were examined and the molecular mechanisms underlying the curcumin-mediated effects in TPC-1 cells were investigated. Our results revealed that the miR-301a-5p/STAT3 axis may be an important signaling pathway in mediating the antitumor effects of curcumin on TPC-1 cells. The present study may provide new insights into the antitumor effects of curcumin in PTC.

\section{Materials and methods}

Cell lines and cell culture. A PTC cell line (TPC-1) was obtained from Shanghai Huiying Biological Technology Co., Ltd. A human thyroid cancer cell line (BCPAP-R, the BRAF mutation) and a human normal cell line (Nthy-ori3-1) were obtained from the Chinese Academy of Medical Sciences. The cells were cultured in Dulbecco's modified Eagle's medium (DMEM; Sigma-Aldrich; Merck KGaA) supplemented with $10 \%$ fetal bovine serum (FBS; Thermo Fisher Scientific, Inc.) in an incubator containing $5 \% \mathrm{CO}_{2}$ at $37^{\circ} \mathrm{C}$ (Thermo Fisher Scientific, Inc.) (33).

MiRNAs, vectors, and cell transfection. Transfections were performed using $50 \mathrm{nM}$ miR-301a-3p mimic (5'-CGAAAC UGUUAUGAUAACGUGAC-3'), 100 nM miR-301a-3p inhibitor (5'-GUCACGUUAUCAUAACAGUUCG-3'), $50 \mathrm{nM}$ miR-301a-3p negative control mimic (NC mimic; 5'-UUCUCC GAACGUGUCACGU-3') and $100 \mathrm{nM}$ miR-301a-3p inhibitor NC (5'-CAGUACUUUUGUGUAGUACAA-3'), which were obtained from Shanghai GenePharma Co., Ltd. The STAT3 overexpression vector (pc-STAT3; $2 \mu \mathrm{g} / \mu \mathrm{l}$ ) was constructed to promote the expression of STAT3 in PTC-1 cells, and the empty vector was used as a control for overexpression vector pc-STAT3. Cell transfection with the miRNA mimics, miRNA inhibitors or vectors was performed using Lipofectamine 3000 (Invitrogen; Thermo Fisher Scientific, Inc.) at $37^{\circ} \mathrm{C}$ for $4 \mathrm{~h}$ according to the manufacturer's protocol. Following transfection for $48 \mathrm{~h}$, subsequent experiments were performed. For the curcumin (Sigma-Aldrich; Merck KGaA) treatments, the cells were incubated with different concentrations of curcumin $(0,2.5,5,10,20$ and $40 \mu \mathrm{M})$ at $37^{\circ} \mathrm{C}$ for $24 \mathrm{~h}$.

Cell-Counting Kit-8 (CCK-8) assay. Cell viability was detected by the CCK- 8 assay (Beyotime Institute of Biotechnology) according to the manufacturer's instructions, as previously described (17). Briefly, TPC-1 and BCPAP cells were seeded into 96-well plates at a density of $1 \times 10^{4}$ cells/well, cultured overnight and treated for $24 \mathrm{~h}$. After treatment, $10 \mu \mathrm{l}$ of CCK-8 solution was added to each well of the 96-well plate and incubated at $37^{\circ} \mathrm{C}$ for $4 \mathrm{~h}$. The optical density (OD) was measured at $450 \mathrm{~nm}$ with a microplate reader (BioTek Instruments, Inc). The half-maximal inhibitory concentrations $\left(\mathrm{IC}_{50}\right)$ were estimated based on the dose-response curve.

Wound healing assay. TPC-1 and BCPAP cells were seeded in 6-well plates ( $70-80 \%$ confluency) and cultured at $37^{\circ} \mathrm{C}$ for $48 \mathrm{~h}$ until they reached full confluence. The full confluent monolayers were scratched with $200-\mu 1$ pipette tips. Then, the cells were cultured in DMEM supplemented with $10 \%$ FBS (34). The wound area was recorded via light microscopy observations at 0 and $24 \mathrm{~h}$ and images were captured using the Lionheart ${ }^{\mathrm{TM}} \mathrm{FX}$ automated live cell imager (BioTek Instruments, Inc.).

Transwell assay. TPC-1 and BCPAP cell suspensions were counted and then diluted to $5 \times 10^{4}$ cells $/ \mathrm{ml}$. Transwell chambers were placed into a 24-well plate (Costar; Corning, Inc.), and the cell suspension was seeded into the apical chambers; DMEM medium $(0.5 \mathrm{ml})$ containing $10 \%$ FBS was added to 
the basolateral chambers, and the plates were incubated in an incubator containing $5 \% \mathrm{CO}_{2}$ at $37^{\circ} \mathrm{C}$ for $24 \mathrm{~h}$. The migrating cells on the basal side of the membranes were treated with paraformaldehyde $(4 \%)$ at $37^{\circ} \mathrm{C}$ for $15 \mathrm{~min}$, and crystal violet $(0.1 \%)$ was used to stain the cells at $37^{\circ} \mathrm{C}$ for $5 \mathrm{~min}$, followed by washing with PBS. Images of each chamber were captured using a light microscopy Lionheart ${ }^{\mathrm{TM}} \mathrm{FX}$ automated live cell imager, and the number of cells in each field was used to obtain an average number. For the cell invasion assay, the Transwell chambers were precoated with Matrigel (BD Biosciences) at $37^{\circ} \mathrm{C}$ for $15 \mathrm{~min}$, and a similar protocol was followed.

Western blot assay. Proteins were extracted from the cells using RIPA (Beyotime Institute of Biotechnology), and the concentration was determined according to standard protocols of BCA protein assay kits (Beyotime Institute of Biotechnology). The total protein in the supernatants (40 $\mu \mathrm{g} /$ well) was separated by $10 \%$ SDS-PAGE and then transferred to PVDF membranes. After blocking with 5\% skim milk for $1 \mathrm{~h}$ at room temperature, the membranes were incubated overnight at $4{ }^{\circ} \mathrm{C}$ with the following antibodies: Rabbit anti-matrix metallopeptidase (MMP)-2 (1:1,000; cat. no. 40994; Cell Signaling Technology, Inc.), rabbit anti-MMP-9(1:1,000; cat. no. 13667; Cell Signaling Technology, Inc.), rabbit anti-E-cadherin (1:10,000; cat. no. ab40772; Abcam), rabbit anti-N-cadherin (1:10,000; cat. no. ab76011; Abcam), rabbit anti-vimentin $(1: 1,000$; cat. no. ab92547; Abcam), rabbit anti-fibronectin (1:1,000; cat. no. ab2413; Abcam), rabbit p-anti-JAK1 (1:1,000; cat. no. ab215338; Abcam), rabbit p-anti-JAK2 (1:1,000; cat. no. ab32101; Abcam), rabbit p-anti-JAK3 (1:5,000; cat. no. ab61102; Abcam), rabbit p-anti-STAT1 (1:1,000; cat. no. ab109461; Abcam), rabbit p-anti-STAT2 (1:1,000; cat. no. ab53132; Abcam), rabbit anti-JAK1 (1:1,000; cat. no. ab133666; Abcam), rabbit anti-JAK2 (1:1,000; cat. no. ab108596; Abcam), rabbit anti-JAK3 (1:5,000; cat. no. ab45141; Abcam), rabbit anti-STAT1 (1:1,000; cat. no. ab109320; Abcam), rabbit anti-STAT2 (1:1,000; cat. no. ab233177; Abcam), rabbit anti-STAT3 (1:1,000; cat. no. ab68153; Abcam) and rabbit $\beta$-actin (1:5,000; cat. no. ab8226; Abcam). After 3 washes with TBS $+0.1 \%$ Tween-20, the immunoblots were incubated for $1 \mathrm{~h}$ at room temperature with alkaline phosphatase-labeled goat anti-rabbit antibodies (1:1,000; cat. no. 14708; Cell Signaling Technology, Inc.). The immunoreactive bands were visualized using an enhanced chemiluminescence reagent (Beyotime Institute of Biotechnology). The blots were semiquantified by ImageJ software (version 1.47; National Institutes of Health).

Real-time quantitative polymerase chain reaction ( $R T$ - $q P C R)$. Total RNA was isolated from cells using TRIzol ${ }^{\circledR}$ solution (Takara Biotechnology Co., Ltd.) according to the manufacturer's protocol. First-strand cDNA was synthesized from the total RNA using the PrimeScript ${ }^{\mathrm{TM}}$ RT Reagent Kit (Takara Biotechnology Co., Ltd.) according to the manufacturer's protocol. The expression level of the miR-301a-3p miRNA was assessed using an RT-qPCR system (ABI Prism 7300; Applied Biosystems; Thermo Fisher Scientific, Inc.) with 2X TaqMan Fast qPCR Master Mix (Sangon Biotech, Co., Ltd.), according to the manufacturer's protocol. Specific primers were designed and synthesized by Sangon Biotech Co., Ltd. The relative
miRNA levels were calculated using the $2^{-\Delta \Delta \mathrm{Cq}}$ method (35) and normalized to the U6 level. All the samples were analyzed in at least 3 parallel reactions. The primer sequences were as follows: miR-301a-3p (Accession number: NR_029842) forward, 5'-ACACTCCAGCTGGGCAGTGCAATAGTATTG TC-3' and reverse, 5'-CTCAACTGGTGTCGTGGA-3'; and U6 (Accession number: NR_004394) forward, 5'-CTCGCT TCGGCAGCACATA-3' and reverse, 5'-AACGATTCACGA ATTTGCGT-3'. The following thermocycling conditions were used: Initial denaturation at $95^{\circ} \mathrm{C}$ for $3 \mathrm{~min} ; 40$ cycles at $95^{\circ} \mathrm{C}$ for $5 \mathrm{sec}, 60^{\circ} \mathrm{C}$ for $15 \mathrm{sec}$ and $72^{\circ} \mathrm{C}$ for $30 \mathrm{sec}$.

miR-301a-3p differential analysis by starBase. Differentially expressed miR-301a-3p between 509 thyroid carcinoma and 58 normal thyroid tissues was analyzed by starBase (version 2.0; http://starbase.sysu.edu.cn/starbase2/) (36). Filters were set up as: miRNA, has-miR-301a-3p; cancer, thyroid carcinoma; chart type, box plot; data scale, $\log _{2}$-scale. The expression data of cancers were downloaded from The Cancer Genome Atlas (TCGA) project via Genomic Data Commons Data Portal (37). The data were grouped by cancer and normal type.

Bioinformatics and luciferase reporter assays. StarBase online software was used to predict the targeted binding sites of miRNAs in mRNAs. Subsequently, the targeted binding relationships between miR-301a-3p and STAT3 were predicted. A pmirGLO Dual-Luciferase Expression Vector (Promega Corporation) that included wild-type (WT) or mutant (MUT) 3'-untranslated region (UTR) binding sites of the STAT3 sequence, named WT-STAT3 or MUT-STAT3, respectively, was constructed and co-transfected with miR-301a-3p mimics, inhibitors and the corresponding negative controls into 293T cells (Bank of Type Culture Collection of the Chinese Academy of Sciences). A total of $48 \mathrm{~h}$ after transfection, the results were obtained using a Dual-Luciferase Reporter Assay System (Promega Corporation), according to the manufacturer's protocol. Firefly luciferase activity was normalized to Renilla luciferase activity and all experiments were performed in triplicate.

Statistical analysis. All the experiments were performed with three independent biological replicates. The data are expressed as the mean \pm standard deviation (SD). The $\mathrm{IC}_{50}$ values in cells were calculated following non-linear regression on the dose-response curves. Multigroup comparisons were performed using one-way analysis of variance (ANOVA) followed by Tukey's post hoc test, and comparisons between two groups were performed using unpaired t-tests. $\mathrm{P}<0.05$ was considered to indicate a statistically significant difference and the analyses were conducted with SPSS 20.0 software (IBM Corp.).

\section{Results}

Curcumin suppresses PTC cell viability. The antitumor effect of curcumin on PTC cells was examined by CCK-8 assay. TPC-1 and BCPAP-R cells were treated with different concentrations of curcumin $(0,2.5,5,10,20$ and $40 \mu \mathrm{M})$ for $24 \mathrm{~h}$. As demonstrated in Fig. 1A and C, curcumin significantly reduced the viability of the PTC cells in a concentration-dependent 

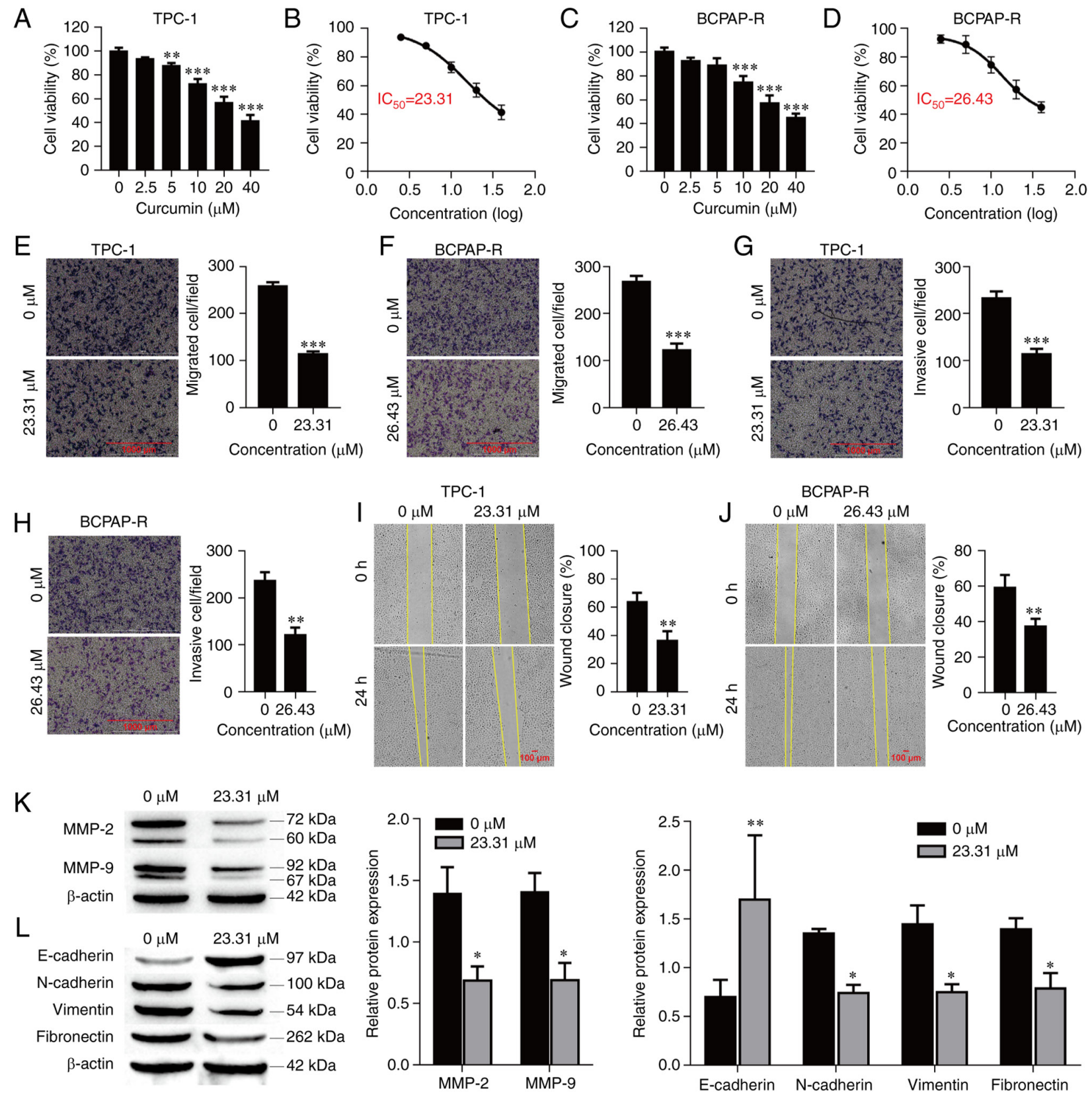

Figure 1. Curcumin inhibits cell viability, invasion and migration, and suppresses EMT in TPC-1 cells. (A) TPC-1 and (C) BCPAP-R cell viability was examined by Cell Counting Kit-8 assay. The $\mathrm{IC}_{50}$ values in (B) TPC-1 and (D) BCPAP-R cells were calculated following non-linear regression on the dose-response curves. (E) TPC-1 and (F) BCPAP-R cell migration was determined by Transwell cell migration assays and analyzed at a magnification of x20. (G) TPC-1 and $(\mathrm{H})$ BCPAP-R cell invasion was determined by Transwell cell invasion assays and analyzed at a magnification of x20. Percentages (\%) of (I) TPC-1 and (J) BCPAP-R cell wound closures in wound healing assays at a magnification of x20. (K) The expression of MMP-2 and MMP-9 was determined by western blot analysis. (L) The expression of EMT-related markers was determined by western blot analysis. The data are expressed as the mean \pm SD. ${ }^{*} \mathrm{P}<0.05$, ${ }^{* * *} \mathrm{P}<0.01$ and ${ }^{* * *} \mathrm{P}<0.001$, vs. $0 \mu \mathrm{M}$. EMT, epithelial-mesenchymal transition; $\mathrm{IC}_{50}$, half-maximal inhibitory concentrations.

manner. The data indicated antitumor activity, and based on the dose-response curve, the $\mathrm{IC}_{50}$ of curcumin was approximately 23.31 and $26.43 \mu \mathrm{M}$ for the TPC-1 and BCPAP-R cells, respectively, at $24 \mathrm{~h}$ (Fig. $1 \mathrm{~B}$ and D). Hence, cells treated with 23.31 and $26.43 \mu \mathrm{M}$ curcumin for $24 \mathrm{~h}$ were used for the following experiments.

Curcumin inhibits cell migration, invasion and EMT. To further explore the functions of curcumin in PTC cells, its effects on the migration and invasion of TPC-1 and BCPAP-R cells were examined. Curcumin treatment at a concentration of $23.31 \mu \mathrm{M}$ or $26.43 \mu \mathrm{M}$ for $24 \mathrm{~h}$ significantly inhibited cell migration and invasion compared with the control treatment (Fig. 1E-H; $\mathrm{P}<0.001$, respectively). Similarly, the wound healing assay demonstrated that curcumin significantly reduced cell migration (Fig. 1I and J; $\mathrm{P}<0.01$, respectively). The protein levels of MMP-2 and MMP-9 were evaluated in TPC-1 cells treated with curcumin. Curcumin significantly reduced the protein expression of MMP-2 and MMP-9 (Fig. 1K; P<0.01, respectively). In addition, EMT-related markers (N-cadherin, E-cadherin, vimentin and fibronectin) were also detected by western blot analysis. As revealed in Fig. 1L, compared with the control 
treatment, curcumin treatment decreased the protein expression levels of $\mathrm{N}$-cadherin $(\mathrm{P}=0.047)$, vimentin $(\mathrm{P}=0.021)$ and fibronectin $(\mathrm{P}=0.048)$ but increased the protein expression level of E-cadherin $(\mathrm{P}<0.01)$. These data indicated that curcumin suppressed cell migration and invasion as well as MMP-2, MMP-9 and EMT marker expression in PTC cells.

Curcumin inhibits cell viability, migration, invasion and EMT by upregulating miR-301a-3p. The expression of miR-301a-3p in thyroid carcinoma was validated using starBase. As revealed in Fig. 2A, the expression of miR-301a-3p was downregulated in thyroid carcinoma $(\mathrm{P}=0.043)$ and significantly downregulated in TPC-1 and BCPAP-R cells compared with Nthy-ori-1 cells (Fig. 2B; P<0.001). Next, to explore the potential mechanism by which curcumin drives the progression of PTC cells, the expression of miR-301a-3p was detected after treatment with different concentrations of curcumin $(0,5,10,20$ and $40 \mu \mathrm{M})$ for $24 \mathrm{~h}$. As observed in Fig. 2C, curcumin markedly increased the expression of miR-301a-3p in a concentration-dependent manner. To further examine the function of miR-301a-3p in TPC-1 cells, cell viability, migration and invasion were analyzed. As anticipated, transfection of miR-301a-3p inhibitors significantly decreased the expression of miR-301a-3p compared with transfection of the NC group (Fig. 2D; $\mathrm{P}<0.001$ ). The cell viability of TPC-1 cells transfected with the miR-301a-3p inhibitors was higher than that of the of the TPC-1 cells transfected with NC $(\mathrm{P}=0.048)$, and the viability was decreased after curcumin treatment $(\mathrm{P}<0.001)$ but increased after miR-301a-3p inhibitor transfection (Fig. 2E; $\mathrm{P}<0.001$ ). Moreover, the addition of the miR-301a-3p inhibitors significantly increased the migration and invasion abilities of the TPC -1 cells $(\mathrm{P}=0.027$ and $\mathrm{P}=0.021$, respectively) compared with the $\mathrm{NC}$ group, and cell migration and invasion were inhibited after curcumin treatment $(\mathrm{P}<0.001$, respectively); these effects were reversed by the transfection of miR-301a-3p inhibitors (Fig. $2 \mathrm{~F}$ and G; $\mathrm{P}<0.001$ and $\mathrm{P}<0.01$, respectively). Similarly, the wound healing assay demonstrated that curcumin significantly inhibited wound closure, which was enhanced by the transfection of miR-301a-3p inhibitors (Fig. 2H; P<0.001).

The protein expression levels of MMP-2 and MMP-9 were increased in the miR-301a-3p inhibitor group compared with the NC group $(\mathrm{P}<0.01$ and $\mathrm{P}=0.033$, respectively). Furthermore, the MMP-2 and MMP-9 protein expression levels were decreased after curcumin treatment $(\mathrm{P}<0.01$, respectively) but increased after miR-301a-3p inhibitor transfection (Fig. 3A; $\mathrm{P}=0.029$ and $\mathrm{P}<0.01$, respectively). In addition, the EMT-related markers $\mathrm{N}$-cadherin and fibronectin were increased in the miR-301a-3p inhibitor group compared with the NC group $(\mathrm{P}<0.01$, respectively); moreover, these markers were decreased after curcumin treatment $(\mathrm{P}<0.01$, respectively), and this effect was reversed by the transfection of miR-301a-3p inhibitors (Fig. 3B; $\mathrm{P}=0.032$ and $\mathrm{P}=0.040$, respectively). Conversely, compared with the control group, E-cadherin protein expression was decreased in the miR-301a-3p inhibitor group $(\mathrm{P}=0.038)$; however, E-cadherin protein expression increased after curcumin treatment $(\mathrm{P}<0.01)$, and this effect was reversed by the transfection of miR-301a-3p inhibitors ( $\mathrm{P}<0.01)$. Interestingly, miR-301a-3p inhibitor transfection did not affect vimentin expression $(\mathrm{P}=0.954)$, however curcumin significantly decreased vimentin expression $(\mathrm{P}<0.01)$ and was reversed by the addition of miR-301a-3p inhibitors $(\mathrm{P}<0.01)$. Collectively, these data indicated that curcumin suppressed TPC-1 cell migration and invasion by upregulating miR-301a-3p expression.

miR-301a-3p directly targets STAT3. The bioinformatics software starBase was used to identify potential targets of miR-301a-3p, and STAT3 was selected due to its role in cancer metastasis. To confirm the interaction between miR-301a-3p and STAT3, a luciferase reporter vector containing the WT or MUT 3'UTR of STAT3 was constructed (Fig. 4A). Overexpression of miR-301a-3p significantly suppressed the luciferase activity of the WT reporter vector (Fig. 4B; P<0.001) but did not affect the luciferase activity of the mutant reporter vector in 293T cells. Furthermore, transfection of miR-301a-3p mimics resulted in a significant increase of the expression of miR-301a-3p in TPC-1 cells compared with the NC mimics group (Fig. 4C; $\mathrm{P}<0.01$ ), and overexpression of miR-301a-3p also significantly suppressed the protein expression level of STAT3 in TPC-1 cells (Fig. 4D; P<0.001). Collectively, the aforementioned results indicated that miR-301a-3p directly targeted the STAT3 gene.

Curcumin inhibits cell viability, migration and invasion by regulating the miR-301a-3p/STAT3 axis. The next aim was to determine the functional interaction of miR-301a-3p and STAT3 during the curcumin-mediated inhibition of TPC-1 cell viability, migration and invasion. Firstly, the successful overexpression of STAT3 was confirmed through the transfection of pc-STAT3 vector (Fig. 5A; P<0.001). Subsequently, the expression of STAT3 was significantly suppressed by curcumin treatment $(\mathrm{P}<0.001)$, which was significantly reversed by STAT3 overexpression in TPC-1 cells $(\mathrm{P}=0.040)$, and miR-301a-3p overexpression also significantly suppressed STAT3 protein expression (Fig. 5B; $\mathrm{P}<0.001)$. Overexpression of miR-301a-3p significantly decreased cell viability compared with NC group $(\mathrm{P}<0.001)$; in addition, cell viability was also significantly suppressed by curcumin treatment $(\mathrm{P}<0.001)$, and this effect was significantly reversed by STAT3 overexpression in TPC-1 cells (Fig. 5C; $\mathrm{P}<0.001$ ). Moreover, cell migration and invasion were inhibited by miR-301a-3p overexpression and curcumin treatment $(\mathrm{P}<0.001$, respectively), and the overexpression of STAT3 alleviated the inhibitory effect of curcumin on cell migration and invasion (Fig. 5D and E; $\mathrm{P}=0.018$ and $\mathrm{P}=0.028$, respectively). Similarly, the wound healing assay demonstrated that the miR-301a-3p mimics and curcumin significantly reduced cell migration $(\mathrm{P}<0.001)$, and the overexpression of STAT3 reversed the inhibitory effect of curcumin on cell migration (Fig. 5F; P=0.047). These data indicated that curcumin suppressed TPC-1 cell migration and invasion by regulating the miR-301a-3p/STAT3 axis.

Curcumin inhibits MMP-2, MMP-9 and EMT marker expression and suppresses the JAK/STAT pathway by regulating the miR-301a-3p/STAT3 axis. The protein expression levels of MMP-2, MMP-9 and EMT-related markers (N-cadherin, vimentin and fibronectin) were decreased in the miR-301a-3p mimic and curcumin groups compared with the $\mathrm{NC}$ group ( $\mathrm{P}<0.001$, respectively), and the overexpression of STAT3 reversed the inhibitory effect of curcumin on protein 
A hsa-miR-301a-3p with 509 cancer and 58 normail samples in THCA

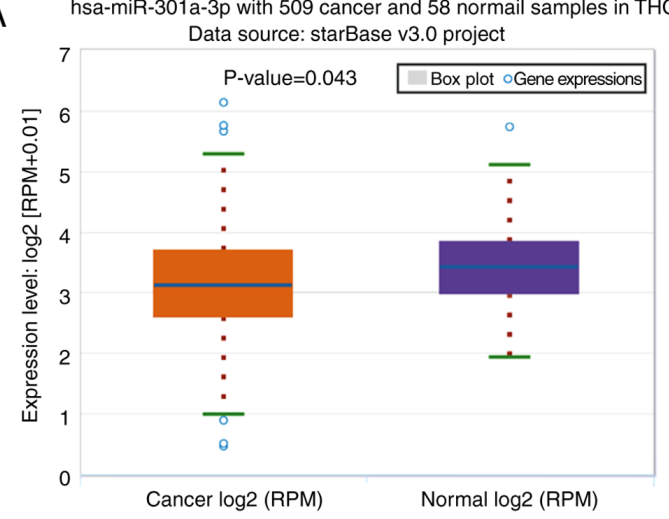

B

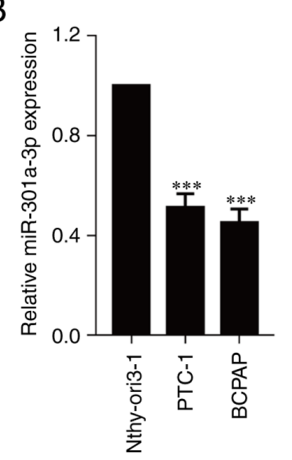

$\mathrm{C}$

$\mathrm{E}$

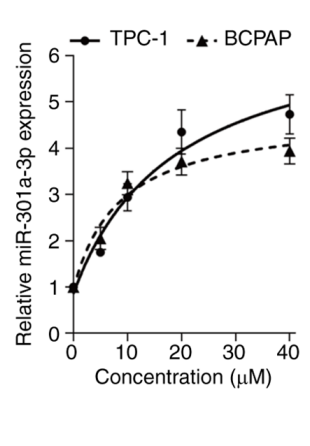

$\mathrm{D}$

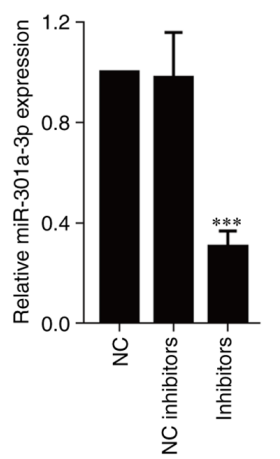

$\mathrm{F}$

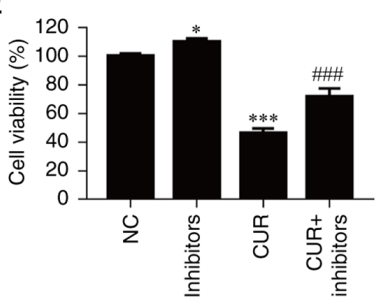

$\mathrm{F} \quad \mathrm{NC}$

Inhibitors

CUR

CUR+inhibitors

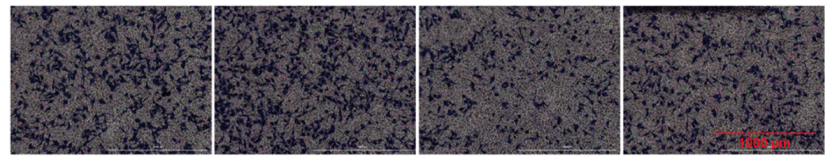

G

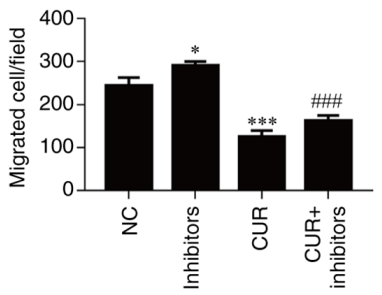

$\mathrm{NC}$

Inhibitors

CUR

CUR+inhibitors

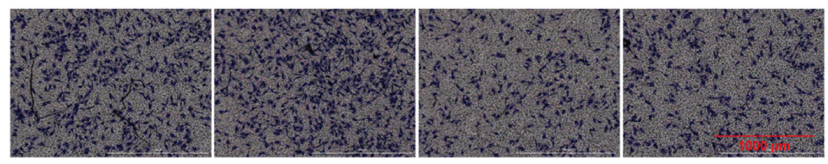

$\mathrm{H}$
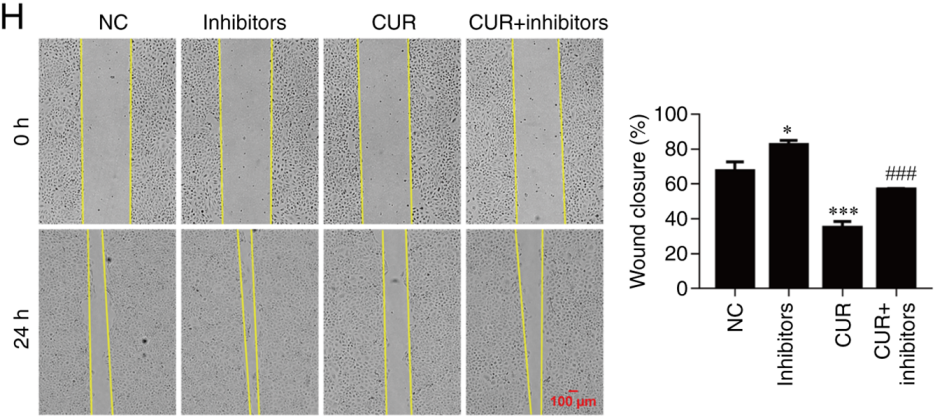

Figure 2. Curcumin inhibits cell viability, migration, and invasion by upregulating miR-301a-3p. (A) Validation of miR-301a-3p expression in THCA using starBase. (B) The expression of miR-301a-3p was determined by real-time quantitative PCR. ${ }^{* * *} \mathrm{P}<0.001$, vs. Nthy-ori3-1 cells. (C and D) The expression of miR-301a-3p was determined by real-time quantitative PCR. (E) Cell viability was examined by CCK-8 assay. (F) Cell migration was determined by Transwell cell migration assays and analyzed at a magnification of x20. (G) Cell invasion was determined by Transwell cell invasion assays and analyzed at a magnification of $\mathrm{x} 20 .(\mathrm{H})$ Percentange $(\%)$ of wound closure in wound healing assays was analyzed at a magnification of $\mathrm{x} 20$. The data are expressed as the mean \pm SD. ${ }^{*} \mathrm{P}<0.05$ and ${ }^{* * *} \mathrm{P}<0.001$, vs. NC; ${ }^{\# \#} \mathrm{P}<0.01$ and ${ }^{\# \# \#} \mathrm{P}<0.001$, vs. CUR. miR, microRNA; THCA, thyroid carcinoma; NC, negative control; inhibitors, miR-301a-3p inhibitors; CUR, curcumin $(23.31 \mu \mathrm{M})$.

expression (Fig. 6A and B; $\mathrm{P}<0.05$ ). Conversely, the E-cadherin protein expression was increased after the miR-301a-3p and curcumin treatments $(\mathrm{P}<0.001)$, but the overexpression of
STAT3 reversed the effect of curcumin on the promotion of protein expression $(\mathrm{P}=0.028)$. STAT3 is one of the pivotal proteins involved in the JAK/STAT signaling pathway (38). 

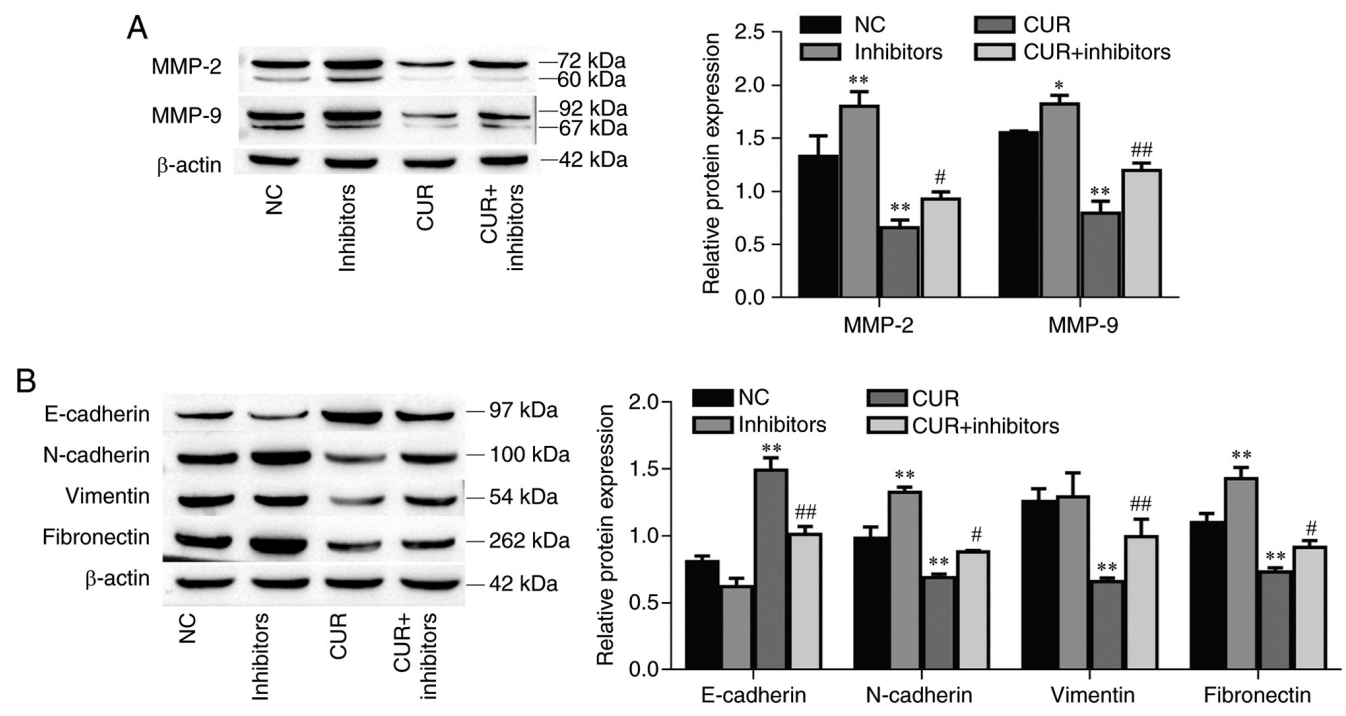

Figure 3. Curcumin inhibits MMP-2, MMP-9 and EMT-related marker expression by upregulating miR-301a-3p. (A) The expression of MMP-2 and MMP-9 was determined by western blot analysis. (B) The expression of EMT-related markers was determined by western blotting. The data are expressed as the mean \pm SD. ${ }^{~} \mathrm{P}<0.05$ and ${ }^{* *} \mathrm{P}<0.01$, vs. NC; ${ }^{\#} \mathrm{P}<0.05$ and ${ }^{\# \#} \mathrm{P}<0.01$, vs. CUR. EMT, epithelial-mesenchymal transition; NC, negative control; miR, microRNA; inhibitors, miR-301a-3p inhibitors; CUR, curcumin $(23.31 \mu \mathrm{M})$.
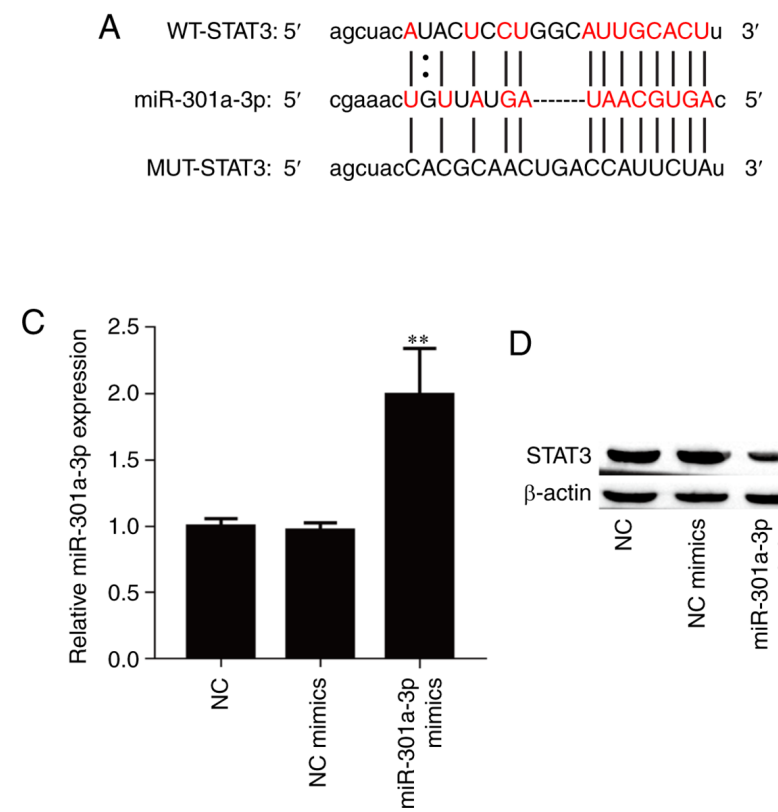

B

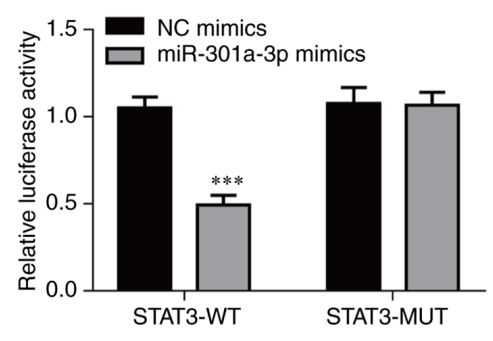

D

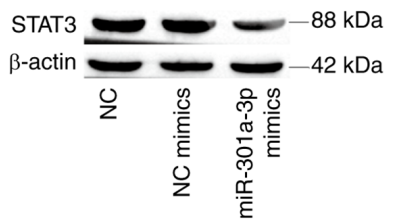

Figure 4. miR-301a-3p directly targets STAT3. (A) Schematic representation of the binding site of miR-301a-3p in STAT3-WT an in STAT3-MUT. (B) Dual-luciferase reporter assays were used to demonstrate that miR-301b-3p can target STAT3. (C) The transfection efficiency of miR-301a-3p mimic was determined by real-time quantitative PCR. (D) The expression of STAT3 was determined by western blot analysis. The data are expressed as the mean \pm SD ${ }^{* * *} \mathrm{P}<0.01$ and ${ }^{* * *} \mathrm{P}<0.001$, vs. NC or NC mimics. miR, microRNA; STAT, signal transducer and activator of transcription; WT, wild-type; MUT, mutant; $\mathrm{NC}$, negative control.

Therefore, the effects of curcumin on the JAK/STAT signaling pathway were investigated. As demonstrated in Fig. 6C, the levels of phosphorylated JAK1, JAK2, JAK3, STAT1 and STAT2 were significantly suppressed by curcumin treatment $(\mathrm{P}<0.001$, respectively), which was effectively reversed by the overexpression of STAT3 in TPC- 1 cells $(\mathrm{P}<0.05)$, and the overexpression of miR-301a-3p also significantly suppressed the levels of phosphorylated JAK1, JAK2, JAK3, STAT1 and STAT2 $(\mathrm{P}<0.001$, respectively). Collectively, these data indicated that curcumin inhibited MMP-2, MMP-9 and EMT-related marker expression, and suppressed the JAK/STAT pathway by regulating the miR-301a-3p/STAT3 axis.

\section{Discussion}

Curcumin has been revealed to serve as a potent antitumor drug for the treatment of multiple cancers, including PTC $(14,39)$. It has already been suggested that curcumin suppresses the survival, invasion and migration of cancer cells (39). In 


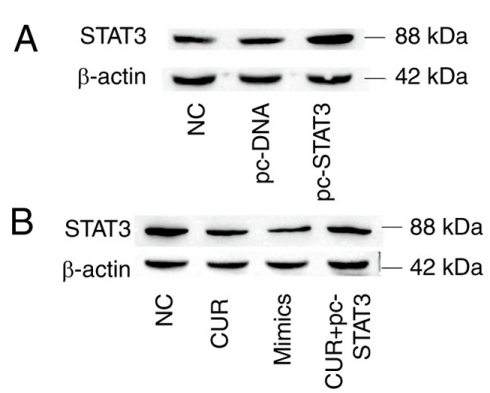

D
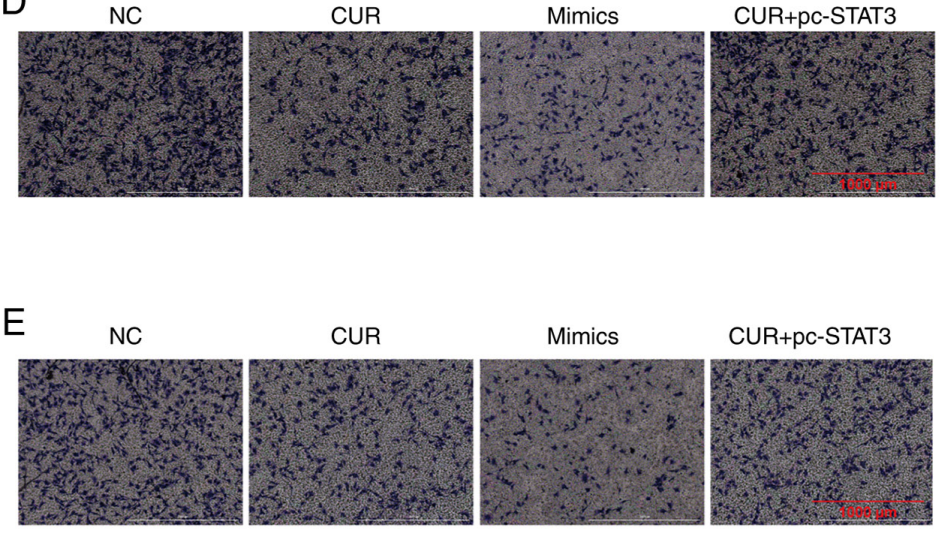

$\mathrm{F}$

NC

CUR
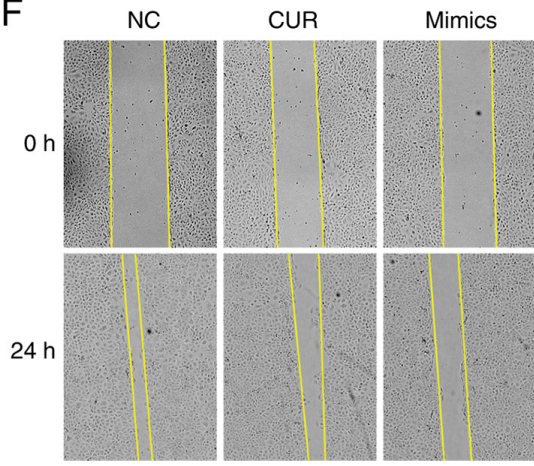

CUR+PC-STAT3
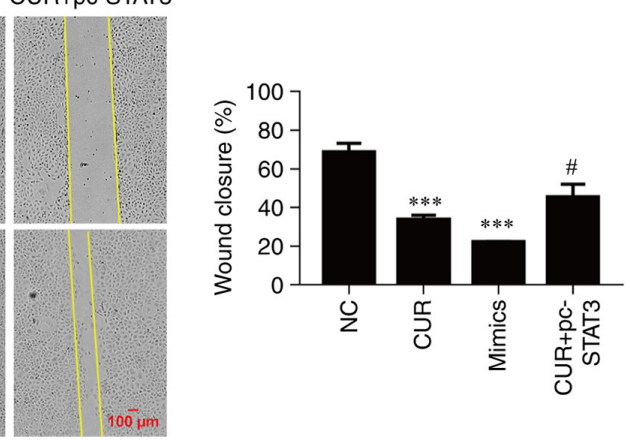

Figure 5. Curcumin inhibits cell viability, migration and invasion by regulating the miR-301a-3p/STAT3 axis. (A) The transfection efficiency of pc-STAT3 was determined by western blot analysis. (B) The expression of STAT3 was determined by western blotting. (C) Cell viability was examined by Cell Counting Kit-8 assay. (D) Cell migration was determined by Transwell cell migration assays and analyzed at a magnification of x20. (E) Cell invasion was determined by Transwell cell invasion assays and analyzed at a magnification of x20. (F) Percentage (\%) of wound closure in wound healing assays was analyzed at a magnification of $\mathrm{x} 20$. The data are expressed as the mean $\pm \mathrm{SD}$. ${ }^{* * *} \mathrm{P}<0.001$, vs. NC; ${ }^{*} \mathrm{P}<0.05$ and ${ }^{\# \# \#} \mathrm{P}<0.001$, vs. CUR. miR, microRNA; STAT, signal transducer and activator of transcription; pc-STAT3, overexpression of STAT3; NC, negative control; CUR, curcumin (23.31 $\mu \mathrm{M})$; mimics, miR-301a-3p mimics.

the present study, the $\mathrm{IC}_{50}$ of curcumin was approximately 23.31 and $26.43 \mu \mathrm{M}$ in TPC-1 and BCPAP-R cells at $24 \mathrm{~h}$, respectively. Previous studies have reported that $20-50 \mu \mathrm{M}$ of curcumin could significantly promote the apoptosis of PTC cells (17,40-42). For example, Khan et al determined that 20 and $10 \mu \mathrm{M}$ of curcumin significantly decreased BCPAP-R and TPC-1 cell viability, respectively (17); Schwertheim et al reported that 50,25 and $25 \mu \mathrm{M}$ curcumin significantly inhibited TPC-1, BHT-101 and FTC-133 cell viability, respectively (40). Thus, 23.31 $\mu \mathrm{M}$ (TPC-1 cells) and $26.43 \mu \mathrm{M}$ (BCPAP-R cells) curcumin were used in experiments.

Curcumin has been demonstrated to possess antitumor, anti-inflammatory, antioxidant and antimicrobial properties (43-45). Typically, curcumin is involved in multiple anticancer processes (46). Results of a previous study have demonstrated that miRNAs may act as protective regulators of curcumin antitumor activity (47). The present study revealed that miR-301a-3p was expressed at lower levels in PTC and was upregulated by curcumin. miR-301a-3p has been revealed to regulate multiple biological processes, including cell proliferation, differentiation, biological development and numerous metabolic processes in organisms $(48,49)$. Furthermore, it was demonstrated that inhibition of miR-301a-3p reversed the inhibitory effects of curcumin on the viability, migration and invasion of TPC-1 cells. Thus, miR-301a-3p was identified as a protective regulator in PTC cells. The curcumin-mediated regulation of miRNA expression, including the activation/inactivation of miRNA transcription, the regulation of associated signaling pathways and the methylation/demethylation of miRNAs, is complex (50). Spadotto et al revealed that extensive methylation of complexes led to downregulated miR-301a expression (51). Curcumin has been demonstrated to cause epigenetic modulation of miR-203 expression by demethylating the 

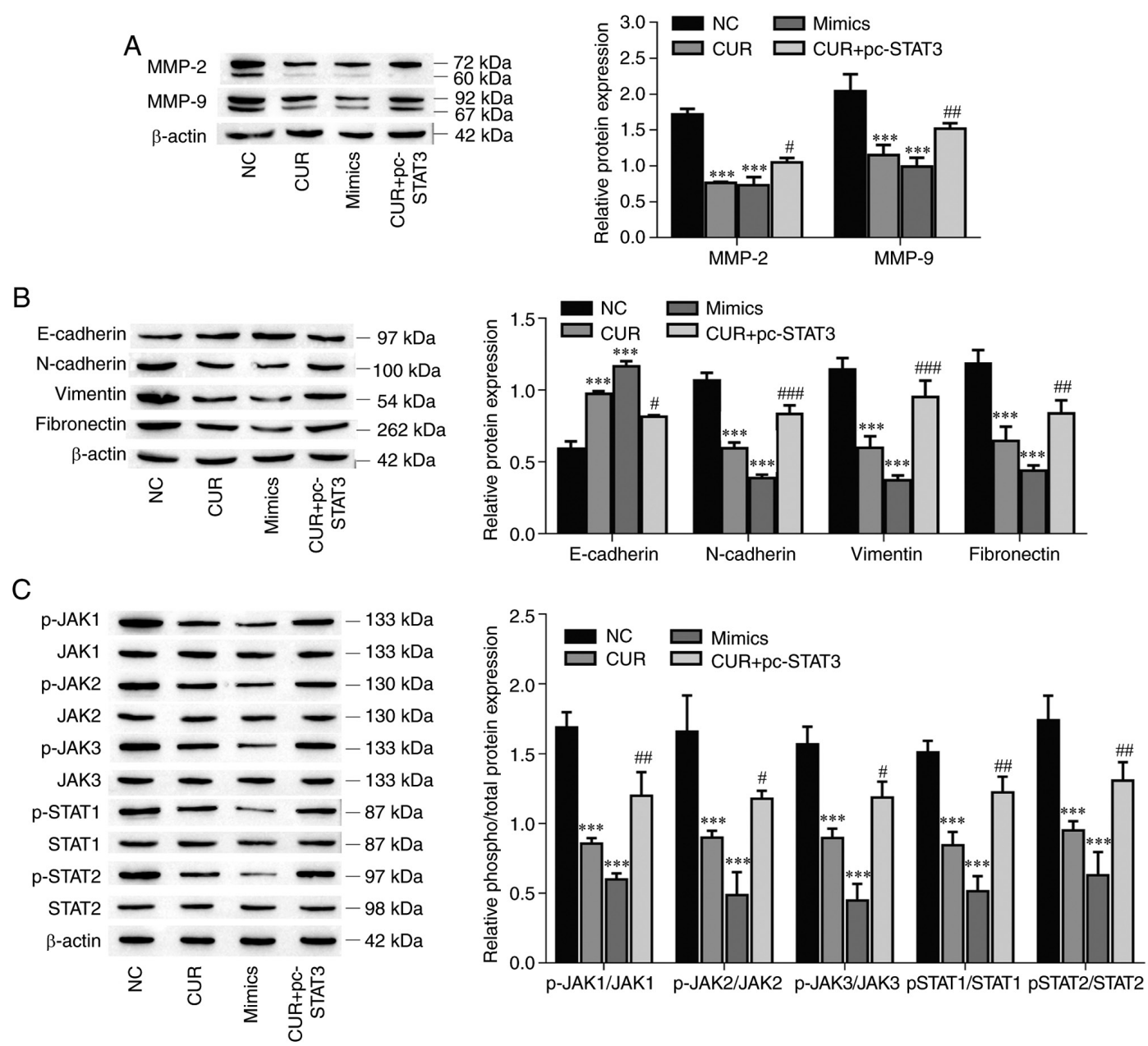

Figure 6. Curcumin inhibits MMP-2, MMP-9 and EMT, and suppresses the JAK/STAT pathway by regulating the miR-301a-3p/STAT3 axis. (A) The expression of MMP-2 and MMP-9 was determined by western blotting. (B) The expression of EMT-related markers was determined by western blot analysis. (C) The levels of phosphorylated and total protein components of the JAK/STAT signaling pathway were determined by western blotting. The data are expressed as the mean \pm SD. ${ }^{* * * *} \mathrm{P}<0.01$, vs. NC; ${ }^{\# P}<0.05,{ }^{* \# *} \mathrm{P}<0.01$ and ${ }^{\# \# \#} \mathrm{P}<0.001$, vs. CUR. EMT, epithelial-mesenchymal transition; JAK/STAT, Janus kinase/signal transducer and activator of transcription; miR, microRNA; NC, negative control; CUR, curcumin (23.31 $\mu \mathrm{M})$; mimics, miR-301a-3p mimics; pc-STAT3, overexpression of STAT3.

miR-203 promoter in bladder cancer (52). Curcumin could increase miR-301a-3p expression via decreased methylation of the complex and/or miR-301a-3p promoter in PTC.

Curcumin has been revealed to inhibit cell proliferation, migration and invasion by activating the JAK2/STAT3 signaling pathway, as it has been reported for different human malignancies, such as retinoblastoma and ovary and thyroid cancers $(17,53,54)$. Our study further demonstrated that curcumin inhibited the JAK/STAT signaling pathway by upregulating miR-301a-3p expression and that miR-301a-3p directly targeted STAT3. These observations indicated that miR-301a-3p was a suppressor of STAT3 protein expression and the JAK/STAT signaling pathway in TPC-1 cells. STAT3 is considered to be one of the most common oncogenes in human cancers and plays a key role in PTC progression $(17,55)$. It was further demonstrated that curcumin and miR-301a-3p mimics reduced the levels of phosphorylated JAK1, JAK2, JAK3, STAT1 and STAT2 via the targeting of STAT3 by miR-301a-3p, whereas the overexpression of STAT3 abolished the suppressive effect of curcumin on this signaling pathway. Thus, the miR-301a-3p/STAT3 axis was identified as an efficient regulator of JAK/STAT signaling pathway in TPC-1 cells.
It has been reported that curcumin regulates EMT in human cancers, including PTC $(41,56,57)$. Notably, EMT is considered to be a critical event in cancer cell migration and invasion, and curcumin has been reported to inhibit PTC cell migration and invasion $(25,58,59)$, indicating that curcumin inhibits PTC cell migration and invasion by inhibiting EMT. In the present study, it was demonstrated that curcumin inhibited EMT, migration and invasion of PTC cells. MiR-301a-3p inhibitors increased EMT and reversed the inhibitory effects of curcumin in EMT of TPC-1 cells. These observations indicated that curcumin inhibited EMT by upregulating miR-301a-3p expression. It has been reported that curcumin suppressed EMT through the miR-200c/EPM5 axis and the ERK5/AP-1 and TET1-NKD-Wnt signaling pathways (60-62). Furthermore, our results indicated that the targeting of STAT3 by miR-301a-3p and the overexpression of STAT3 also reversed the inhibitory effects of curcumin on EMT in TPC-1 cells. Thus, it was revealed that curcumin inhibited EMT by regulating the miR-301a-3p/STAT3 axis.

In our study, it was demonstrated that curcumin inhibited STAT3 expression. Furthermore, the overexpression of STAT3 reversed the inhibitory effects of curcumin on the viability, 
migration and invasion of TPC-1 cells. It has been reported that suppression of STAT3 activity or expression inhibits human cancer progression $(55,63,64)$. Curcumin has been demonstrated to promote PTC cell apoptosis by increasing DNA damage, endoplasmic reticulum stress and the PI3K/Akt signaling pathway $(16,42,59)$. These observations demonstrated that targeting STAT3 is a potential therapeutic target for PTC. In the present study, it was revealed that curcumin inhibited the viability of TPC-1 cells by regulating the miR-301a-3p/STAT3 axis. An increasing number of studies has reported that curcumin leads to cell cycle arrest at the G2/M phase in PTC cells $(40,42,65)$. Therefore, it was theorized that curcumin inhibited the viability of PTC cells by affecting the $\mathrm{G} 2 / \mathrm{M}$ phase of the cell cycle. It has been reported that curcumin promotes PTC cell apoptosis and inhibits PTC cell migration and invasion $(16,25,40-42,57-59,65)$. A recent study reported that curcumin mediated BCPAP-R and TPC-1 cell apoptosis and stemness by targeting the JAK/STAT3 signaling pathway (17). Notably, the present study revealed that curcumin downregulated STAT3 expression by upregulating miR-301a-3p expression in TPC-1 cells. Previous studies have demonstrated that STAT3 promotes tumour progression in PTC (66-68). The results of the present study provided strong evidence that curcumin decreases the expression of STAT3 and suppresses the viability, migration and invasion of PTC cells via upregulating miR-301a-3p.

However, the potential role and underlying mechanism of curcumin in PTC was only investigated in vitro, and several limitations should also be considered. Curcumin affects miRNAs that have been reported to be involved in human cancer progression (15). Curcumin may affect the expression of additional miRNAs in PTC cells (40). In future studies, microarray assays may be used to profile the miRNAs that could be regulated by curcumin in TPC-1 cells. In addition, the present study only selected STAT3 as a target of miR-301a-3p and TPC-1 cells as the cell model for further study, but miR-301a-3p may also target other genes. Consequenlty, future studies may investigate more targets of miR-301a-3p to further reveal the underlying antitumor mechanisms of the antitumor effects of curcumin on additionl types of PTC cells. Moreover, whether the use of curcumin with chemotherapeutic reagents currently used to treat PTC could potentiate the antitumor effects and reduce drug toxicity will be investigated in our future studies.

In summary, curcumin suppressed the cell viability, migration, invasion and EMT of TPC-1 cells. Moreover, curcumin treatment increased miR-301a-3p expression and inhibited STAT3 expression. Overexpression of miR-301a-3p inhibited cell viability, migration, invasion, and EMT and the JAK/STAT signaling pathway by targeting STAT3, and miR-301a-3p inhibitors and STAT3 overexpression reversed the curcumin-induced cell viability, migration, invasion and EMT of TPC-1 cells. Collectively, curcumin played an anticancer role in TPC-1 cells by regulating miR-301a-3p/STAT3, indicating that curcumin is a promising oncotherapeutic agent. These findings may provide a possible strategy for the clinical treatment of PTC.

\section{Acknowledgements}

Not applicable.

\section{Funding}

The present study was supported by the Scientific Research Fund of Yunnan Education Department (grant no. 2019J1262).

\section{Availability of data and materials}

The datasets used and/or analyzed during the current study are available from the corresponding author on reasonable request.

\section{Authors' contributions}

YiL, DK, YZ and JM conceived and designed the research. YiL, DK, YZ, SL, Yal, LD, NZ and JM performed the experiments and analyzed the data. YiL, DK and JM wrote the manuscript. YiL, SL and YaL interpreted the data. YZ, SL and $\mathrm{JM}$ reviewed/edited the manuscript. All authors read and approved the final manuscript.

\section{Ethics approval and consent to participate}

Not applicable.

\section{Patient consent for publication}

Not applicable.

\section{Competing interests}

The authors declare that they have no competing interests.

\section{References}

1. Siegel RL, Miller KD and Jemal A: Cancer statistics, 2020. CA Cancer J Clin 70: 7-30, 2020.

2. Wang J, Yu F, Shang Y, Ping Z and Liu L: Thyroid cancer: Incidence and mortality trends in China, 2005-2015. Endocrine 68: 163-173, 2020.

3. Laha D, Nilubol N and Boufraqech M: New therapies for advanced thyroid cancer. Front Endocrinol (Lausanne) 11: 82, 2020.

4. Kumar A and Bal CS: Differentiated thyroid cancer. Indian J Pediatr 70: 707-713, 2003.

5. Rao SN, Zafereo M, Dadu R, Busaidy NL, Hess K, Cote GJ, Williams MD, William WN, Sandulache V, Gross N, et al: Patterns of treatment failure in anaplastic thyroid carcinoma. Thyroid 27: 672-681, 2017.

6. Berretta M, Della Pepa C, Tralongo P, Fulvi A, Martellotta F, Lleshi A, Nasti G, Fisichella R, Romano C, De Divitiis C, et al: Use of complementary and alternative medicine (CAM) in cancer patients: An Italian multicenter survey. Oncotarget 8: 24401-24414, 2017.

7. Han YG, Ma LG, Zhao L, Feng W and Zheng X: Rosmarinic inhibits cell proliferation, invasion and migration via up-regulating miR-506 and suppressing MMP2/16 expression in pancreatic cancer. Biomed Pharmacother 115: 108878, 2019.

8. Zhao J, Fang Z, Zha Z, Sun Q, Wang H, Sun M and Qiao B: Quercetin inhibits cell viability, migration and invasion by regulating miR-16/HOXA10 axis in oral cancer. Eur J Pharmacol 847: 11-18, 2019.

9. Perna A, De Luca A, Adelfi L, Pasquale T, Varriale B and Esposito T: Effects of different extracts of curcumin on TPC1 papillary thyroid cancer cell line. BMC Complement Altern Med 18: 63, 2018.

10. Zhou JJ, Zheng JY, Cheng XQ, Xin GZ, Wang SL and Xie T: Chemical markers' knockout coupled with UHPLC-HRMS-based metabolomics reveals anti-cancer integration effects of the curcuminoids of turmeric (Curcuma longa L.) on lung cancer cell line. J Pharm Biomed Anal 175: 112738, 2019. 
11. Buhrmann C, Popper B, Kunnumakkara AB, Aggarwal BB and Shakibaei M: Evidence that calebin a, a component of Curcuma longa suppresses NF-B mediated proliferation, invasion and metastasis of human colorectal cancer induced by TNF- $\beta$ (lymphotoxin). Nutrients 11: 2904, 2019.

12. Huang W, Li X, Wang D, Sun Y, Wang Q, Bu Y and Niu F: Curcumin reduces LPS-induced septic acute kidney injury through suppression of lncRNA PVT1 in mice. Life Sci 254 $117340,2020$.

13. Huang G, Yan Y, Xu D, Wu J, Xu C, Fu L and Lin B: Curcumin-loaded nanoMOFs@CMFP: A biological preserving paste with antibacterial properties and long-acting, controllable release. Food Chem 337: 127987, 2021.

14. Zhang CY,Zhang L, Yu HX, Bao JD, Sun Z and Lu RR: Curcumin inhibits invasion and metastasis in K1 papillary thyroid cancer cells. Food Chem 139: 1021-1028, 2013.

15. Mirzaei H, Masoudifar A, Sahebkar A, Zare N, Sadri Nahand J, Rashidi B, Mehrabian E, Mohammadi M, Mirzaei HR and Jaafari MR: MicroRNA: A novel target of curcumin in cancer therapy. J Cell Physiol 233: 3004-3015, 2018.

16. Zhang L, Cheng X, Xu S, Bao J and Yu H: Curcumin induces endoplasmic reticulum stress-associated apoptosis in human papillary thyroid carcinoma BCPAP cells via disruption of intracellular calcium homeostasis. Medicine (Baltimore) 97: e11095, 2018.

17. Khan AQ, Ahmed EI, Elareer N, Fathima H, Prabhu KS Siveen KS, Kulinski M, Azizi F, Dermime S, Ahmad A, et al: Curcumin-mediated apoptotic cell death in papillary thyroid cancer and cancer stem-like cells through targeting of the JAK/STAT3 signaling pathway. Int J Mol Sci 21: 438, 2020.

18. Celano M, Rosignolo F, Maggisano V, Pecce V, Iannone M, Russo D and Bulotta S: MicroRNAs as biomarkers in thyroid carcinoma. Int J Genomics 2017: 6496570, 2017.

19. Aragon Han $\mathrm{P}$, Weng $\mathrm{CH}$, Khawaja HT, Nagarajan $\mathrm{N}$, Schneider EB, Umbricht CB, Witwer KW and Zeiger MA: MicroRNA expression and association with clinicopathologic features in papillary thyroid cancer: A systematic review. Thyroid 25: 1322-1329, 2015

20. Zhang $\mathrm{N}, \mathrm{Hu} \mathrm{X}, \mathrm{Du} \mathrm{Y}$ and $\mathrm{Du} \mathrm{J}$ : The role of miRNAs in colorectal cancer progression and chemoradiotherapy. Biomed Pharmacother 134: 111099, 2020.

21. Hu J, Ruan J, Liu X, Xiao C and Xiong J: MicroRNA-301a-3p suppressed the progression of hepatocellular carcinoma via targeting VGLL4. Pathol Res Pract 214: 2039-2045, 2018.

22. Jiao X, Ye J, Wang X, Yin X, Zhang G and Cheng X: KIAA1199, a target of micoRNA-486-5p, promotes papillary thyroid cancer invasion by influencing epithelial-mesenchymal transition (EMT). Med Sci Monit 25: 6788-6796, 2019.

23. Zhou P, Irving A, Wu H, Luo J, Aguirre J, Costa M, Khamsuree M, Gerads N and Liu WB: Validation of microRNA-188-5p inhibition power on tumor cell proliferation in papillary thyroid carcinoma. Cell Transplant 29: 963689720918300, 2020.

24. Jiao DM, Yan L, Wang LS, Hu HZ, Tang XL, Chen J, Wang J, Li Y and Chen QY: Exploration of inhibitory mechanisms of curcumin in lung cancer metastasis using a miRNA-transcription factor-target gene network. PLoS One 12: e0172470, 2017.

25. Allegri L, Rosignolo F, Mio C, Filetti S, Baldan F and Damante G: Effects of nutraceuticals on anaplastic thyroid cancer cells J Cancer Res Clin Oncol 144: 285-294, 2018.

26. Carthew RW and Sontheimer EJ: Origins and mechanisms of miRNAs and siRNAs. Cell 136: 642-655, 2009.

27. Morgan EL and Macdonald A: Manipulation of JAK/STAT signalling by high-risk HPVs: Potential therapeutic targets for HPV-associated malignancies. Viruses 12: 977, 2020.

28. Qing X, Tan GL, Liu HW, Li W, Ai JG, Xiong SS, Yang MQ and Wang TS: LINC00669 insulates the JAK/STAT suppressor SOCS1 to promote nasopharyngeal cancer cell proliferation and invasion. J Exp Clin Cancer Res 39: 166, 2020.

29. Couto JP Daly L, Almeida A, Knauf JA, Fagin JA, Sobrinho-Simões M, Lima J, Máximo V, Soares P, Lyden D and Bromberg JF: STAT3 negatively regulates thyroid tumorigenesis. Proc Natl Acad Sci USA 109: E2361-E2370, 2012.

30. Yang L, Tan Z, Li Y, Zhang X, Wu Y, Xu B and Wang M: Insulin-like growth factor 1 promotes proliferation and invasion of papillary thyroid cancer through the STAT3 pathway. J Clin Lab Anal 34: e23531, 2020

31. Zhang T, He L, Wang Z, Dong W, Sun W, Qin Y, Zhang P and Zhang H: Calcitriol enhances Doxorubicin-induced apoptosis in papillary thyroid carcinoma cells via regulating VDR/PTPN2/p-STAT3 pathway. J Cell Mol Med 24: 5629-5639, 2020 .
32. Kong D, Li A, Liu Y, Cui Q, Wang K, Zhang D, Tang J, Du Y, Liu Z, Wu G and Wu K: SIX1 Activates STAT3 signaling to promote the proliferation of thyroid carcinoma via EYA1. Front Oncol 9: 1450, 2019

33. Zhou Y, Liu S, Luo Y, Zhang M, Jiang X and Xiong Y: LncRNA MAPKAPK5-AS1 promotes proliferation and migration of thyroid cancer cell lines by targeting miR-519e-5p/YWHAH. Eur J Histochem 64: 3177, 2020.

34. Sun Y, Zhang L and Zhang S: MicroRNA-124-3p inhibits tumourigenesis by targeting mitogen-activated protein kinase 4 in papillary thyroid carcinoma. Cell Biochem Funct 38: $1017-1024,2020$

35. Livak KJ and Schmittgen TD: Analysis of relative gene expression data using real-time quantitative PCR and the 2(-Delta Delta C(T)) method. Methods 25: 402-408, 2001.

36. Li JH, Liu S, Zhou H, Qu LH and Yang JH: StarBase v2.0: Decoding miRNA-ceRNA, miRNA-ncRNA and protein-RNA interaction networks from large-scale CLIP-Seq data. Nucleic Acids Res 42 (Database Issue): D92-D97, 2014.

37. Wang Z, Jensen MA and Zenklusen JC: A Practical guide to the cancer genome atlas (TCGA). Methods Mol Biol 1418: 111-141, 2016.

38. Owen KL, Brockwell NK and Parker BS: JAK-STAT signaling: A double-edged sword of immune regulation and cancer progression. Cancers 11: 2002, 2019.

39. Giordano A and Tommonaro G: Curcumin and cancer. Nutrients 11: 2376, 2019.

40. Schwertheim S, Wein F, Lennartz K, Worm K, Schmid KW and Sheu-Grabellus SY: Curcumin induces G2/M arrest, apoptosis, $\mathrm{NF}-\kappa \mathrm{B}$ inhibition, and expression of differentiation genes in thyroid carcinoma cells. J Cancer Res Clin Oncol 143: 1143-1154, 2017.

41. Zhang CY, Zhang L, Yu HX, Bao JD and Lu RR: Curcumin inhibits the metastasis of K1 papillary thyroid cancer cells via modulating E-cadherin and matrix metalloproteinase-9 expression. Biotechnol Lett 35: 995-1000, 2013.

42. Zhang L, Cheng X, Gao Y, Bao J, Guan H, Lu R, Yu H, Xu Q and Sun Y: Induction of ROS-independent DNA damage by curcumin leads to G2/M cell cycle arrest and apoptosis in human papillary thyroid carcinoma BCPAP cells. Food Funct 7: 315-325, 2016.

43. Liu L, Fu Y, Zheng Y, Ma M and Wang C: Curcumin inhibits proteasome activity in triple-negative breast cancer cells through regulating p300/miR-142-3p/PSMB5 axis. Phytomedicine 78: 153312,2020

44. Nozari E, Moradi A and Samadi M: Effect of atorvastatin, curcumin, and quercetin on miR-21 and miR-122 and their correlation with TGF $\beta 1$ expression in experimental liver fibrosis. Life Sci 259: 118293, 2020.

45. Sharifi-Rad J, Rayess YE, Rizk AA, Sadaka C, Zgheib R, Zam W, Sestito S, Rapposelli S, Neffe-Skocińska K, Zielińska D, et al: Turmeric and its major compound curcumin on health: Bioactive effects and safety profiles for food, pharmaceutical, biotechnological and medicinal applications. Front Pharmacol 11: 01021, 2020.

46. Ashrafizadeh M, Rafiei H, Mohammadinejad R, Afshar EG, Farkhondeh T and Samarghandian S: Potential therapeutic effects of curcumin mediated by JAK/STAT signaling pathway: A review. Phytother Res 34: 1745-1760, 2020

47. Wang N, Feng T, Liu X and Liu Q: Curcumin inhibits migration and invasion of non-small cell lung cancer cells through up-regulation of miR-206 and suppression of PI3K/AKT/mTOR signaling pathway. Acta Pharm 70: 399-409, 2020.

48. Zhang L, Zhang Y, Zhu H, Sun X, Wang X, Wu P and Xu X: Overexpression of miR-301a-3p promotes colorectal cancer cell proliferation and metastasis by targeting deleted in liver cancer-1 and runt-related transcription factor 3. J Cell Biochem 120: 6078-6089, 2019

49. Xia X, Zhang K, Luo G, Cen G, Cao J, Huang K and Qiu Z: Downregulation of miR-301a-3p sensitizes pancreatic cancer cells to gemcitabine treatment via PTEN. Am J Transl Res 9: 1886-1895, 2017.

50. Zhou S, Zhang S, Shen H, Chen W, Xu H, Chen X, Sun D, Zhong S, Zhao J and Tang J: Curcumin inhibits cancer progression through regulating expression of microRNAs. Tumour Biol 39: $1010428317691680,2017$.

51. Spadotto V, Giambruno R, Massignani E, Mihailovic M, Maniaci M, Patuzzo F, Ghini F, Nicassio F and Bonaldi T: PRMT1-mediated methylation of the microprocessor-associated proteins regulates microRNA biogenesis. Nucleic Acids Res 48: 96-115, 2020 
52. Saini S, Arora S, Majid S, Shahryari V, Chen Y, Deng G, Yamamura S, Ueno $\mathrm{K}$ and Dahiya R: Curcumin modulates microRNA-203-mediated regulation of the Src-Akt axis in bladder cancer. Cancer Prev Res (Phila) 4: 1698-1709, 2011.

53. Li Y, Sun W, Han N, Zou Y and Yin D: Curcumin inhibits proliferation, migration, invasion and promotes apoptosis of retinoblastoma cell lines through modulation of miR-99a and JAK/STAT pathway. BMC Cancer 18: 1230, 2018.

54. Kim MJ, Park KS, Kim KT and Gil EY: The inhibitory effect of curcumin via fascin suppression through JAK/STAT3 pathway on metastasis and recurrence of ovary cancer cells. BMC Women's Health 20: 256, 2020.

55. Wu Z, Liu H, Sun W, Du Y, He W, Guo S, Chen L, Zhao Z, Wang P, Liang H and Deng J: RNF180 mediates STAT3 activity by regulating the expression of RhoC via the proteasomal pathway in gastric cancer cells. Cell Death Dis 11: 881, 2020.

56. Bahrami A, Majeed M and Sahebkar A: Curcumin: A potent agent to reverse epithelial-to-mesenchymal transition. Cell Oncol 42: 405-421, 2019

57. Zhang L, Cheng X, Gao Y, Zhang C, Bao J, Guan H, Yu H, Lu R, $\mathrm{Xu} \mathrm{Q}$ and Sun Y: Curcumin inhibits metastasis in human papillary thyroid carcinoma BCPAP cells via down-regulation of the TGF- $\beta /$ Smad2/3 signaling pathway. Exp Cell Res 341: 157-165, 2016.

58. Tan C, Zhang L, Cheng X, Lin XF, Lu RR, Bao JD and Yu HX: Curcumin inhibits hypoxia-induced migration in K1 papillary thyroid cancer cells. Exp Biol Med (Maywood) 240: 925-935, 2015

59. Xu X, Qin J and Liu W: Curcumin inhibits the invasion of thyroid cancer cells via down-regulation of PI3K/Akt signaling pathway. Gene 546: 226-232, 2014.

60. Wang H, Cai XL and Ma L: Curcumin modifies epithelial-mesenchymal transition in colorectal cancer through regulation of miR-200c/EPM5. Cancer Manag Res 12 : 9405-9415, 2020.

61. Zhang T, Zhao L, Zhang T, Wu W, Liu J, Wang X, Wan Y, Geng H, Sun X, Qian W and Yu D: Curcumin negatively regulates cigarette smoke-induced renal cell carcinoma epithelial-mesenchymal transition through the ERK5/AP-1 pathway. Onco Targets Ther 13: 9689-9700, 2020.
62. Lu Y, Zhang R, Zhang XJ, Zhang B and Yao Q: Curcumin may reverse 5-fluorouracil resistance on colonic cancer cells by regulating TET1-NKD-Wnt signal pathway to inhibit the EMT progress. Biomed Pharmacother 129: 110381, 2020.

63. Huang Q, Zhong Y, Dong H, Zheng Q, Shi S, Zhu K, Qu X, $\mathrm{Hu}$ W, Zhang X and Wang Y: Revisiting signal transducer and activator of transcription 3 (STAT3) as an anticancer target and its inhibitor discovery: Where are we and where should we go? Eur J Med Chem 187: 111922, 2020.

64. Sasidharan Nair V, Toor SM, Ali BR and Elkord E: Dual inhibition of STAT1 and STAT3 activation downregulates expression of PD-L1 in human breast cancer cells. Expert Opin Ther Targets 22: 547-557, 2018.

65. Esposito T, Lucariello A, Hay E, Contieri M, Tammaro P, Varriale B, Guerra G, De Luca A and Perna A: Effects of curcumin and its adjuvant on TPC1 thyroid cell line. Chem Biol Interact 305: 112-118, 2019.

66. Shiraiwa K, Matsuse M, Nakazawa Y, Ogi T, Suzuki K, Saenko V, Xu S, Umezawa K, Yamashita S, Tsukamoto K and Mitsutake N: JAK/STAT3 and NF- $\kappa$ B signaling pathways regulate cancer stem-cell properties in anaplastic thyroid cancer cells. Thyroid 29: 674-682, 2019.

67. Wen J, Wang H, Dong T, Gan P, Fang H, Wu S, Li J, Zhang Y, Du R and Zhu Q: STAT3-induced upregulation of lncRNA ABHD11-AS1 promotes tumour progression in papillary thyroid carcinoma by regulating miR-1301-3p/STAT3 axis and PI3K/AKT signalling pathway. Cell Prolif 52: e12569, 2019.

68. Mancikova V, Montero-Conde C, Perales-Paton J, Fernandez A, Santacana M, Jodkowska K, Inglada-Pérez L, Castelblanco E, Borrego S, Encinas M, et al: Multilayer OMIC data in medullary thyroid carcinoma identifies the STAT3 pathway as a potential therapeutic target in RET ${ }^{\mathrm{M} 918 \mathrm{~T}}$ tumors. Clin Cancer Res 23: $1334-1345,2017$.

(i) (5) This work is licensed under a Creative Commons CY NC ND Attribution-NonCommercial-NoDerivatives 4.0 International (CC BY-NC-ND 4.0) License. 